Orthopäde $2021 \cdot 50: 1018-1025$

https://doi.org/10.1007/s00132-021-04182-w

Accepted: 30 September 2021

Published online: 29 October 2021

(c) The Author(s) 2021

\section{Imageless robotic-assisted revision arthroplasty from UKA to TKA}

\section{Surgical technique and case-control study compared with primary robotic TKA}

\author{
Lars-Rene Tuecking ${ }^{1}$ Peter Savov ${ }^{1} \cdot$ Henning Windhagen ${ }^{1} \cdot$ Simon Jennings ${ }^{2}$. \\ Dinesh Nathwani ${ }^{3} \cdot$ Max Ettinger ${ }^{\prime}$ \\ ' Department of Orthopaedic Surgery, Hannover Medical School, Diakovere Annastift, Hannover, Germany \\ ${ }^{2}$ London North West University Healthcare NHS Trust, London, UK \\ ${ }^{3}$ Charing Cross Hospital, Imperial College London, London, UK
}

\title{
Abstract
}

Background and objective: It is evident from the national joint registries that numbers of revision knee arthroplasty operations are rising. The aim of this article is to introduce a new robotic-assisted approach in UKA to TKA revision arthroplasty and investigate the alignment accuracy, implant component use and surgery time and to compare it to primary robotic-assisted TKA arthroplasty.

Methods: This retrospective, case-control study included patients undergoing imageless robotic-assisted revision arthroplasty from UKA to TKA $(n=20)$ and patients undergoing image-less robotic-assisted primary TKA (control group, $n=20$ ) from $11 / 2018$ to $07 / 2020$. The control group was matched based on the BMI and natural alignment. Comparison of groups was based on postoperative alignment, outlier rate, tibial insert size, lateral bone resection depth, incision-to-wound closure time. All surgeries were performed by a single senior surgeon using the same bi-cruciate stabilizing TKA system. Statistical analysis consisted of parametric t-testing and Fisher's exact test with a level of significance of $p<0.05$.

Results: The two groups showed no differences in mean BMI, natural alignment $(p>0.05)$ and mean overall limb alignment. No outlier was found for OLA and slope analysis. The smallest insert size $(9 \mathrm{~mm})$ was used in $70 \%$ of the cases in the revision group ( $n=14)$ and in $90 \%$ of the cases in the primary group $(n=18, p=0.24)$, distal femoral and tibial resection depth showed no statistical difference $(p>0.05)$. The incision to wound closure time was longer in the revision group but showed no significant difference.

Conclusion: Image-less robotic-assisted revision arthroplasty from UKA to TKA showed a comparable surgery time, and alignment accuracy in comparison to primary roboticassisted TKA. Comparable bone preservation and subsequent tibial insert size use was observed for both groups.

\section{Keywords}

Retrospective study · Case-control study · Accuracy · Revision arthroplasty · Radiographic analysis

Due to increasing numbers of primary implantations of knee endoprostheses, there are also an increasing number of necessary revision procedures. Simultaneously, the number of necessary conversions from UKA to TKA are also increasing. Furthermore, previous clinical outcomes have been shown to be suboptimal after conversion from UKA to TKA compared to primary TKA $[4,5$, $11,13,27]$. In this study, a robotic-assisted technique for conversion of UKA 
to TKA is presented and the accuracy of this technique is compared. The aim is to improve the accuracy of the outcome and to achieve an improvement of the clinical results in the medium term.

\section{Introduction}

Unicompartmental knee arthroplasty (UKA) is an established and successful procedure in contemporary orthopaedic surgery. In addition to the benefits of UKA implantation, such as bone conserving, ligament-sparing procedure, and restoration of normal knee kinematics, the UKA procedure continues to show higher revision rates in national prosthesis registries in comparison to total knee arthroplasty (TKA) procedures $[8,14,15,20]$. The UKA procedure is technically demanding and depends mainly on the experience of the surgeon [17]. The British National Joint Registry (NJR) showed that the revision rate for UKA is significantly higher for surgeons with <30 UKA procedures per year ( $4 \%$ vs. $1 \%$ annual revision rate) [16]. In recent years, higher numbers of UKA procedures have been observed in the NJR for arthroplasty in Germany (EPRD, Endoprothesenregister Deutschland). The number of UKA procedures of all primary knee arthroplasty procedures in 2019 was $13.5 \%$ and about $4 \%$ higher than the previous value in 2015 [6]. For this reason, with an increasing number of UKA procedures, an increase in the number of necessary UKA to TKA revisions can be expected in future years. Furthermore, conflicting evidence still exists regarding clinical outcome and revision rates

\section{Abbreviations}

\begin{tabular}{ll}
$B C S$ & Bi-cruciate stabilized insert \\
$B M I$ & Body mass index \\
$C C K$ & Condylar constrained insert type \\
$E P R D$ & Endoprosthesis Register Germany \\
$I C T$ & Incision to wound closure time \\
$I D F A$ & Lateral distal femoral angle \\
$M C L$ & Medial collateral ligament \\
mPTA & Medial proximal tibial alignment \\
NJR & National Joint Register \\
OLA & Overall limb alignment \\
$P E$ & Polyethylene \\
$R O M$ & Range of movement \\
$T K A$ & Total knee arthroplasty \\
$U K A$ & Unicompartmental knee arthro- \\
& plasty \\
\hline
\end{tabular}

after UKA to TKA procedures, especially when compared with primary TKA procedures [4, 5, 11, 13, 17, 21, 27]. Isolated case series and case-control studies have demonstrated comparable clinical outcomes and revision rates for UKA to TKA procedures compared with primary TKA procedures $[17,21]$. In contrast, recent registry studies from Sweden and Norway and further meta-analyses showed reduced clinical outcomes and higher rerevision rates for UKA to TKA procedures compared to primary TKA $[4,5,11,13$, 27]. Some authors suspected the reason for this is the mostly necessary use of augmentations, stems and higher inlays due to the increased bone loss compared to primary TKA [27]. In most cases, the increased bone loss during these revision surgeries is due to bone loss during implant removal and resection. As a result, larger inserts and more constrained inserts often have to be used in UKA to TKA revisions [22]. Robotic-assisted primary TKA (RA-TKA) is increasingly gaining popularity in the orthopaedic domain [9]. The main advantages of RA-TKA include improved component alignment and realtime control of soft tissue balance [12, $19,23,26,31]$. The use of RA-TKA in the context of UKA revision is a promising approach to improve the results of these revision procedures. The use of robotic assistance might reduce alignment outlier, intraoperative bone loss, and improve soft tissue balance. For this reason, the aim of this study was to examine the extent to which alignment goals can be achieved and bone-saving surgery can be performed. In addition, the workflow of imageless robotic-assisted UKA revision is presented.

\section{Methods}

\section{Study design}

This retrospective case control study consisted of two groups including a total of 40 patients. The first 20 consecutive cases of robotic-assisted UKA revision procedures from November 2018 to July 2020 were included in the experimental group. A matched control group consisted of 20 patients undergoing primary robotic TKA surgery in the same time interval matched by body mass index $\left(\mathrm{BMI} \pm 5 \mathrm{~kg} / \mathrm{m}^{2}\right)$ and natural overall limb alignment $\left(\mathrm{nOLA} \pm 5^{\circ}\right)$. All surgeries were performed by a single senior surgeon (ME) using a bi-cruciate stabilizing TKA system (Journey II ${ }^{\circledR}$ BCS, Smith \& Nephew, London, UK) and an imageless robotic system $\left(\mathrm{NAVIO}^{\circledR}\right.$, Smith \& Nephew) functionally aligned with respect to the preoperative soft tissue balance and prearthritic anatomy. Cases were analyzed for mode of failure (only UKA cases), used implant and augmentation components, insert type, bi-cruciate stabilized insert (BCS) or condylar constrained insert type (CCK), both are available for the Journey II ${ }^{\circledR}$ BCS prosthesis, postoperative alignment, insert size, lateral bone resection depth, incision to wound closure time (ICT). Radiological analysis consisted of postoperative coronal and sagittal alignment, overall limb alignment (OLA), medial proximal tibia angle (mPTA), lateral distal femoral angle (IDFA) and tibial slope. Radiological analysis consisted of full leg radiographs and true lateral long radiographs. Preoperative natural alignment was either analyzed by full leg radiographs of the contralateral side or by radiographs available prior to primary UKA surgery within the revision group. Standard full leg radiographs prior to primary TKA surgery were used for group matching in the control group. Outliers were defined as valgus overall limb alignment (OLA), severe tibial varus alignment with $\mathrm{mPTA}<87^{\circ}$ or excessive varus overall limb alignment $<175^{\circ}$, and negative slope or $>6^{\circ}$ (aiming for $3^{\circ}$ ). Statistical evaluation was performed using Microsoft Excel 2019 and GraphPad Prism 9 software (GraphPad Software, San Diego, CA, USA). Numeric parameters are described as mean values and standard deviation ( $\pm S D$ ). Group comparisons were done using unpaired t-tests and Fisher's exact test. The level of statistical significance was set at $p \leq 0.05$.

\section{Surgical technique}

Robotic-assisted UKA conversion to TKA and primary RA-TKA were both done with the image-less robotic system NAVIO ${ }^{\mathrm{TM}}$ (Smith \& Nephew, London, UK) using the Journey II BCS prothesis. Primary RA-TKA was performed as described before [7, 

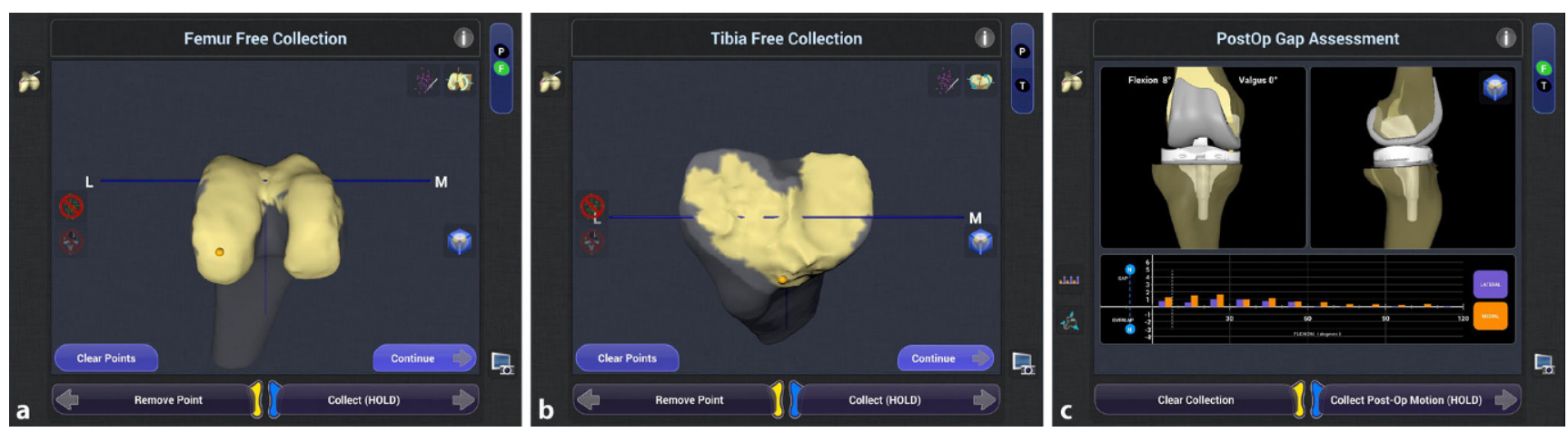

Fig. $1 \Delta$ Intraoperative setting with positioning of the components and postoperative evaluation of soft tissue balance. Intraoperative illustration of anatomy mapping of the femur (a) and the tibia (b) with medial UKAin situ, which is best seen in a with smooth surface in the anatomy mapping screen $(\mathbf{a}, \mathbf{b})$. Postoperative gap assessment of medial and lateral laxity, showing medial (orange) and lateral (purple) gaps within targeted boundaries (c)

23]. In the following, the technique of robotic-assisted UKA conversion to TKA is described:

Due to the imageless system no preoperative CT scan is necessary. Preoperative analysis included full leg radiographs to determine OLA, MPTA and lateral distal femoral angle (IDFA). Additionally, preoperative full leg radiographs prior to UKA implantation were analyzed to determine the natural alignment and joint line height of the patient. If no radiographs prior to UKA implantation existed, full leg radiographs of the contralateral lesser extremity were used to determine the natural alignment. The intraoperative set-up was comparable to the already published setup $[1,7]$.

Step 1: Incision, array positioning, registration and soft tissue balance tracking

A standard medial parapatellar approach is used, while the proximal incision is $1-2 \mathrm{~cm}$ longer to enable pin position on the femur within the same incision. Tibial pins are attached anteromedially $8-10 \mathrm{~cm}$ distal to the tibial plateau to avoid conflicts with the saw. All pins are attached within the bone bicortically. Definition of the hip/ knee center and range of motion (ROM) is done by the developer's standard following the workflow of the NAVIO ${ }^{\mathrm{TM}}$ software (- Fig. 1). Bone tracking with the handpiece and tracking of the soft tissue balance is done with UKA implants in situ. To achieve adequate varus and valgus stress in soft tissue balance, examination spacer blocks or Hohmann hooks can be used.
Assessment of the soft tissue balance in $0^{\circ}$ and $90^{\circ}$ and within the range of flexion from $0^{\circ}$ to $90^{\circ}$ should be tracked carefully to enable perfect soft tissue balance in component positioning.

\section{Step 2: Planning of component alignment}

The aim of any arthroplasty surgery is to reconstruct the joint line and joint line obliquity with respect to the posterior condylar axis. Bone resection depth should not exceed 5.5-6.5 mm lateral (distal + posterior) and, if possible, $7.5-8.5 \mathrm{~mm}$ medial (distal + posterior, note the bone loss during implant removal and the thickness of the implant while assessing the medial cut depth) to avoid joint line proximalization. Alignment of the femoral component is done using the 3D planning intraoperative software to verify reconstruction of the posterior condylar axis and the posterior condylar off-set. The femoral component alignment is adjusted to the preoperative detected natural limb alignment (particularly (DFA). Gaps are then balanced especially in $0^{\circ}$ and $90^{\circ}$ flexion with symmetrical gaps of $1-2 \mathrm{~mm}$ mediolaterally. A slight lateral lift-off in flexion is accepted. Adaption of component alignment to gain optimal gap balancing is mainly done virtually prior to execution of cuts. Exceeding limits of $87^{\circ}$ of mPTA are avoided An mPTA in excess of $87^{\circ}$ should be avoided.

\section{Step 3: Implant removal and bone cutting}

After virtual alignment of the prothesis components the UKA implants are re- moved. The distal cut of the femur is done with the trephine following the intraoperative plan determined preoperatively with the $\mathrm{NAVIO}^{\mathrm{TM}}$ software. Later, 4-in-1 cutting blocks are used to perform the last femoral cuts with navigated cutting blocks. The tibial side can be burred alone or preparing by a bone saw with tibial cutting blocks. A probe can be inserted to check gap balancing and postoperative alignment with the NAVIO ${ }^{\mathrm{TM}}$ system. If balance differences or limitation of full ROM exist, further bone cuts or soft tissue balancing might be done. Bone defects above $5 \mathrm{~mm}$ are compensated with appropriate augmentation.

\section{Step 4: Component implantation}

After correct execution of bone cuts, component implantation can be done following the clinical routine. After cementing a probe inlay (BCS vs. CCK) and different PE thicknesses can be tested to achieve best soft tissue balance and stability.

\section{Results}

Demographic data and alignment analysis results are shown in detail in - Table 1. Both groups showed no difference of mean BMI $(p=0.0149)$ or preoperative natural coronal limb alignment $(p=0.151)$. Reasons of UKA revision were aseptic loosening $(n=8,40 \%)$, secondary instability $(n=5,25 \%)$, osteoarthritis progression ( $n=4,20 \%)$ and valgus overstuffing $(n=3,15 \%)$. Preoperative mPTA and slope showed no differences between groups ( $p=0.627 ; p=0.941$ respectively), 
Table 1 Demographic and results data of both groups

\begin{tabular}{|c|c|c|c|c|c|c|}
\hline & \multicolumn{2}{|c|}{ Robotic UKA revision } & \multicolumn{2}{|c|}{ Robotic primary TKA } & $P$ value \\
\hline \multicolumn{2}{|c|}{ Group size $(n)$} & \multicolumn{2}{|l|}{20} & \multicolumn{2}{|l|}{20} & - \\
\hline \multirow{2}{*}{\multicolumn{2}{|c|}{ Age (years) }} & \multirow[t]{2}{*}{62.4} & \multirow[t]{2}{*}{ \pm 10.2} & \multirow[t]{2}{*}{68.9} & \multirow[t]{2}{*}{ \pm 9.25} & * \\
\hline & & & & & & 0.046 \\
\hline \multirow{2}{*}{\multicolumn{2}{|c|}{ BMI }} & \multirow[t]{2}{*}{31.7} & \multirow[t]{2}{*}{ \pm 6.8} & \multirow[t]{2}{*}{28.8} & \multirow[t]{2}{*}{ \pm 6.6} & n.s. \\
\hline & & & & & & 0.149 \\
\hline \multirow{2}{*}{\multicolumn{2}{|c|}{$\mathrm{ICT}(\min )$}} & \multirow[t]{2}{*}{76.0} & \multirow[t]{2}{*}{ \pm 11.2} & \multirow[t]{2}{*}{69.6} & \multirow[t]{2}{*}{ \pm 16.1} & n.s. \\
\hline & & & & & & 0.052 \\
\hline \multirow[t]{4}{*}{$\operatorname{OLA}\left({ }^{\circ}\right)$} & \multirow{2}{*}{ Preoperative } & \multirow[t]{2}{*}{177.1} & \multirow[t]{2}{*}{ \pm 3.0} & \multirow[t]{2}{*}{175.2} & \multirow[t]{2}{*}{ \pm 2.7} & n.s. \\
\hline & & & & & & 0.151 \\
\hline & \multirow[t]{2}{*}{ Postoperative } & \multirow[t]{2}{*}{178.6} & \pm 1.9 & 176.0 & \pm 2.5 & n.s. \\
\hline & & & & & & 0.221 \\
\hline $\operatorname{mPTA}\left({ }^{\circ}\right)$ & Preoperative & 86.5 & \pm 2.5 & 86.0 & \pm 2.0 & n.s. \\
\hline & & & & & & 0.627 \\
\hline & Postoperative & 88.5 & \pm 1.5 & 88.9 & \pm 1.1 & n.s. \\
\hline & & & & & & 0.837 \\
\hline IDFA $\left({ }^{\circ}\right)$ & Preoperative & 85.5 & \pm 3.2 & 87.8 & \pm 1.7 & * \\
\hline & & & & & & 0.030 \\
\hline & Postoperative & 87.6 & \pm 2.2 & 89.5 & \pm 2.5 & n.s. \\
\hline & & & & & & 0.493 \\
\hline Slope $\left(^{\circ}\right)$ & Preoperative & 4.9 & \pm 3.4 & 4.6 & \pm 2.9 & n.s. \\
\hline & & & & & & 0.941 \\
\hline & Postoperative & 2.3 & \pm 0.6 & 2.6 & \pm 1.7 & n.s. \\
\hline & & & & & & 0.857 \\
\hline Lateral & Distal & 6.5 & \pm 2.0 & 7.1 & \pm 1.7 & n.s. \\
\hline cut depth & & & & & & 0.437 \\
\hline $\mathrm{mm}$ ) & Posterior & 7.8 & \pm 0.7 & 7.5 & \pm 1.3 & n.s. \\
\hline & & & & & & 0.478 \\
\hline Lateral cut & epth (tibial, mm) & 10.0 & \pm 1.6 & 10.0 & \pm 1.1 & n.s. \\
\hline & & & & & & 0.941 \\
\hline Onlay size & & 9.6 & \pm 1.1 & 9.1 & \pm 0.3 & n.s. \\
\hline$(\mathrm{mm})$ & & & & & & 0.112 \\
\hline & $n$ of minimal size & 14 & $(70 \%)$ & 18 & $(90 \%)$ & n.s. \\
\hline & (\% & & & & & 0.240 \\
\hline
\end{tabular}

Values in mean \pm SD

SD standard deviation, UKA unicompartmental knee arthroplasty, TKA total knee arthroplasty, ICT incision to wound-closure time, BMI body mass index, OLA overall limb alignment, $m P T A$ medial proximal tibia angle, IDFA lateral distal femoral angle, Lat. lateral, * significance level, n.s. not significant

Table 2 Outlier rate of postoperative alignment

\begin{tabular}{|c|c|c|c|c|c|c|}
\hline & \multicolumn{2}{|c|}{ Robotic UKA revision } & \multicolumn{2}{|c|}{ Robotic primary TKA } & $P$ value \\
\hline \multicolumn{2}{|l|}{ Group size $(n)$} & \multicolumn{2}{|c|}{20} & \multicolumn{2}{|c|}{20} & - \\
\hline \multirow{2}{*}{$\begin{array}{l}\text { OLA outlier } \\
\text { rate }\end{array}$} & $n$ outlier & \multirow[t]{2}{*}{0} & \multirow[t]{2}{*}{ (0\%) } & \multirow[t]{2}{*}{0} & \multirow[t]{2}{*}{$(0 \%)$} & n.s. \\
\hline & (\% of total) & & & & & - \\
\hline \multirow{2}{*}{$\begin{array}{l}\text { mPTA outlier } \\
\text { rate }\end{array}$} & $n$ outlier & \multirow[t]{2}{*}{1} & \multirow[t]{2}{*}{$(5 \%)$} & \multirow[t]{2}{*}{1} & \multirow[t]{2}{*}{$(5 \%)$} & n.s. \\
\hline & (\% of total) & & & & & $>0.999$ \\
\hline \multirow{2}{*}{$\begin{array}{l}\text { Slope outlier } \\
\text { rate }\end{array}$} & $n$ outlier & \multirow[t]{2}{*}{0} & \multirow[t]{2}{*}{$(0 \%)$} & \multirow[t]{2}{*}{0} & \multirow[t]{2}{*}{$(0 \%)$} & n.s. \\
\hline & (\% of total) & & & & & - \\
\hline
\end{tabular}

Values in mean \pm SD

SD standard deviation, UKA unicompartmental knee arthroplasty, TKA total knee arthroplasty, OLA overall limb alignment, $m$ PTA medial proximal tibial angle, $n$.s. not significant whereas preoperative IDFA showed more valgus alignment in the UKA revision group $\left(85.5^{\circ}\right.$ vs. $\left.87.8^{\circ}, p=0.03\right)$. Incision to wound closure time was higher in the UKA revision group $(76.0 \mathrm{~min}$ vs. $69.6 \mathrm{~min}$ ) but did not reach significance level $(p=0.052)$. Postoperative overall limb alignment showed a slightly more varus limb alignment in the primary TKA group $\left(178.6^{\circ}\right.$ vs. $\left.176.0^{\circ}\right)$, whereas all postoperative alignment parameters showed no statistical differences between the groups (- Table 1). Coronal and sagittal alignment accuracy was found to be similar between groups with no outliers for OLA and slope analysis in both groups (- Fig. 2, - Table 2) and the same outlier rate for mPTA analysis (5\% each, $n=1$ ). Lateral bone cut depth on the tibial and femoral side was comparable in both groups (•Table 1). Standard BCS inserts were used in $100 \%$ of the cases within the primary TKA group and in $90 \%(n=18)$ of the UKA conversion cases $(p=0.49)$. Hence, CCK inserts were used in two cases of the UKA revision group (10\%). No metal augmentation (stems, femoral augments) was used in any of the cases. Mean insert size was slightly higher in the UKA revision group but showed no statistical difference $(9.6 \mathrm{~mm}$ vs. $9.1 \mathrm{~mm}$, $p=0.11$ ). The minimum onlay size was used in most of the cases in the UKA revision group (70\%) but less frequently when compared to the primary TKA group (90\%, $p=0.24)$.

\section{Discussion}

The main result of this retrospective case control study is that robotic-assisted conversion from UKA to TKA is a precise technique in revision arthroplasty and shows similar alignment outcome parameters when compared to primary RATKA.

Alignment accuracy of imageless robotic-assisted UKA conversion to TKA was similar to primary RA-TKA. No radiological outliers for OLA and slope analysis were found in either of the groups. Furthermore, postoperative coronal alignment parameters were all comparable between the groups. In addition to the numerous published studies on improved alignment accuracy in primary robotic-assisted knee 


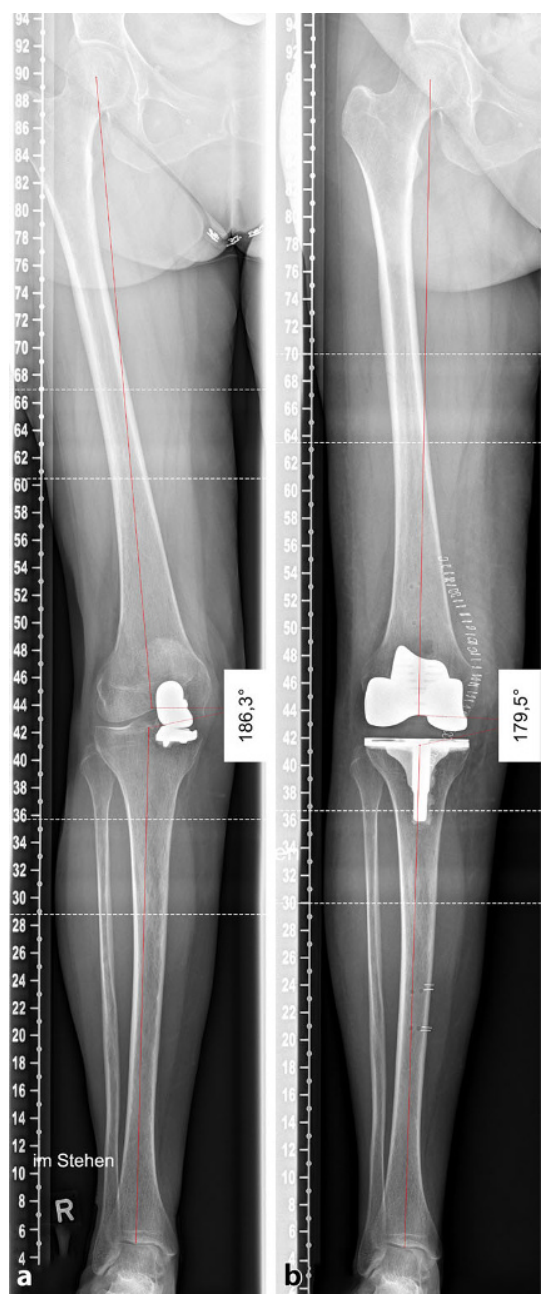

Fig. $2 \Delta$ Preoperative and postoperative alignment after UKA to TKA conversion. Preoperative alignment after UKA implantation (a) shows a valgus overstuffing $\left(6^{\circ}\right)$ with chronic MCL pain. Postoperative alignment (b) after robotic-assisted conversion from UKA to TKA with neutral overall limb alignment

arthroplasty in comparison to conventional TKA $[12,19,23,26,31]$, this case series was able to demonstrate a comparable accuracy and outcome to roboticassisted primary knee arthroplasty. Intraoperative control of component alignment and joint line restoration in revision arthroplasty is often a challenge due to further bone loss or loss of bony reference points after implant removal. Therefore, malalignment after manual UKA conversion to TKA might be reduced with this robotic-assisted approach. Several studies reported a decreased clinical outcome after UKA to TKA revision when compared to primary TKA. These studies showed an increased use of metal augmentation, higher constraint level and increase of polyethylene (PE) thickness in UKA to TKA revision groups [11, 22, 29]. Contrary to the published data, a comparable PE thickness was observed in the current case series for UKA revision in comparison to the primary group and the minimum PE size could be used in the majority of the UKA revision cases (70\%). Additionally, the robotic-assisted approach enables the intraoperative control of soft tissue balance, which might support the use of standard primary implants and minimum size PE onlays instead of constrained implants and onlays. In this context, imagebased robotic-assisted UKA revision also showed comparable and a tendency towards lower PE thickness compared to manual UKA revision in a recently published study [30]. Alignment parameters were not analyzed in that study. Thus, no comparison between imageless and image-based robotic-assisted UKA revision is possible at this point.

Furthermore, in the UKA revision cases in this series, the use of augments or stems was not required. Individual studies report the need for augments or stems in $30-54 \%$ of UKA to TKA revisions $[2,29]$. Additionally, considering the lateral bone resection height in our study, which was comparable between both groups on the tibial and femoral side, it can be assumed that a bone-conserving revision of UKA to TKA is possible by robotic assistance. Nevertheless, two cases of the UKA revision group (10\%) needed a semiconstrained insert, while none of the primary TKA cases needed a CCK insert. Comparable studies by Sarraf et al. [22] and Lunebourg et al. [18] reported the use of constrained implants in $4.2-10.4 \%$ of UKA to TKA revision cases. Nevertheless, the exact level of constraint remains unclear.

Despite the technically more difficult procedure of UKA revision, the time from incision to closure was only slightly higher in the UKA revision group compared to the primary TKA group (76.0 min vs. $69.6 \mathrm{~min}$ ), this difference also did not reach significance level. The incision to wound closure times (ICT) determined in this study are to be compared to frequently published data of single center studies or registry studies $[3,10,24,25,28]$. Published mean ICT range from $67 \mathrm{~min}$ to $104 \mathrm{~min}$, regard- less of whether manual or robotic-assisted TKA was used [3, 10, 24, 25, 28]. Therefore, robotic-assisted UKA conversion is comparable to primary arthroplasty in terms of average time required and does not lead to a significant increase in time from incision to closure.

This study has several limitations. First of all, this was a retrospective study of the first 20 consecutive cases of roboticassisted revision from UKA to TKA analyzing objective operative parameters and alignment outcome only. Thus, the statistical power is reduced. Moreover, the control group was matched by BMI and natural alignment. In some UKA revision cases, preoperative full leg radiographs prior to UKA implantation were not available. Thus, a full leg radiograph of the contralateral side, as performed in the clinical routine, was used to identify the natural alignment. Nevertheless, natural alignment of both lower extremities might differ significantly and therefore might have influenced the classification. Furthermore, no clinical outcome data were obtained because this was not the subject to this study; however, this would give further important information about robotic-assisted UKA revision and should be investigated in further studies. In addition, this study compared UKA revision with primary robotic arthroplasty. No comparison was made between manual and robotic-assisted UKA revision. The aim of this study was to verify whether robotic-assisted UKA revision is comparable to primary arthroplasty in the parameters investigated. The aim was to improve the surgical technique to bring the results of UKA revision in line with primary arthroplasty. Nevertheless, a manual UKA revision comparison group would help to determine whether the roboticassisted technique could achieve an improvement in the accuracy of this operation in a direct comparison.

\section{Conclusion}

- Robotic-assisted revision from UKA to TKA is a reliable approach with accurate component alignment.

- Robotic-assisted revision from UKA to TKA might help to preserve bone stock and might avoid using revision augmentation material and higher constraint implants. 
- Surgery time of robotic-assisted revision from UKA to TKA is comparable to primary TKA.

- Evidence whether these improvements have an impact on clinical outcome is pending and should be further investigated.

\section{Corresponding address}

\section{Dr. med. Lars-Rene Tuecking}

Department of Orthopaedic Surgery, Hannover Medical School, Diakovere Annastift Anna von Borries Str. 1-6, 30625 Hannover, Germany

Lars-rene.tuecking@diakovere.de

Funding. Open Access funding enabled and organized by Projekt DEAL.

\section{Declarations}

Conflict of interest. L.-R. Tuecking, P. Savov, H. Windhagen and $S$. Jennings declare that they have no competing interests. D. Nathwani and M. Ettinger have an educational consultancy agreement with Smith \& Nephew.

Ethical standards. This study was performed with the approval of the relevant ethics committee, in accordance with national law, and in accordance with the Declaration of Helsinki of 1975 (in the current, revised version). This study only consists of retrospective anonymous data analysis.

Open Access. This article is licensed under a Creative Commons Attribution 4.0 International License, which permits use, sharing, adaptation, distribution and reproduction in any medium or format, as long as you give appropriate credit to the original author(s) and the source, provide a link to the Creative Commons licence, and indicate if changes were made. The images or other third party material in this article are included in the article's Creative Commons licence, unless indicated otherwise in a credit line to the material. If material is not included in the article's Creative Commons licence and your intended use is not permitted by statutory regulation or exceeds the permitted use you will need to obtain permission directly from the copyright holder. To view a copy of this licence, visit http://creativecommons.org/licenses/by/4.0/.

\section{References}

1. Battenberg AK, Netravali NA, Lonner JH (2020) A novel handheld robotic-assisted system for unicompartmental knee arthroplasty: surgical technique and early survivorship. J Robot Surg 14:55-60. https://doi.org/10.1007/s11701-018 00907-w

2. Chou DTS, Swamy GN, Lewis JR, Badhe NP (2012) Revision of failed unicompartmental knee replacement to total knee replacement. Knee 19:356-359. https://doi.org/10.1016/j.knee.2011. 05.002

3. Cowley RJ,Frampton C, Young SW (2019)Operating time for total knee arthroplasty in public versus

Bildlose roboterassistierte Revisionsarthroplastik von Schlitten- zu Totalendoprothese. Chirurgische Technik und Fall-Kontroll-Studie im Vergleich zur primären Robotertechnik

Hintergrund und Ziel: Die Zahl der notwendigen Revisionsoperationen für Knietotalendoprothesen (TEP) steigt zunehmend. Ziel dieser Studie ist es, eine neue roboterassistierte Technik in der Revision von Schlitten- (UKA) auf Totalendoprothese (TEP) vorzustellen und die Ausrichtungsgenauigkeit, die Verwendung von Implantatkomponenten sowie die Operationszeit zu untersuchen und mit der primären roboterassistierten Endoprothetik zu vergleichen.

Methodik: Diese retrospektive Fall-Kontroll-Studie schloss Patienten ein, die sich im Zeitraum von 11/2018 bis 07/2020 einer bildlosen roboterassistierten Revisionsoperation von UKA zu TKA $(n=20)$ unterzogen, sowie Patienten, bei denen eine bildlose roboterassistierte primäre TEP-Operation durchgeführt wurde (Kontrollgruppe, $n=20$ ). Die Kontrollgruppe wurde auf Basis des BMI und der natürlichen Beinanatomie gematcht. Der Vergleich der Gruppen basierte auf der postoperativen Komponentenausrichtung, der Ausreißerquote, der Größe des Onlays, der Tiefe der lateralen Knochenresektion und der Schnittnahtzeit. Alle Operationen wurden von einem einzigen Chirurgen unter Verwendung desselben TEP-Systems durchgeführt. Die statistische Auswertung bestand aus einem parametrischen t-Test und einem Fischer-Exakt-Test mit einem Signifikanzniveau von $p<0,05$.

Ergebnisse: Die Gruppen zeigten keinen Unterschied des BMI, der natürlichen Beinanatomie $(p>0,05)$ und der postoperativen Ganzbeinachse. Die Ausreißerquote war in beiden Gruppen für die koronare und sagittale Komponentenausrichtung vergleichbar. Für die Ganzbeinachse und in der Slope-Analyse wurde in beiden Gruppen kein Ausreißer gefunden. Die kleinste Onlaygröße $(9 \mathrm{~mm})$ wurde in $70 \%$ der Fälle in der Revisionsgruppe $(n=14)$ und in $90 \%$ der Fälle in der Primärgruppe $(n=18$, $p=0,24$ ) verwendet. Die distale femorale und tibiale Resektionstiefe zeigte keinen statistischen Unterschied $(p>0,05)$. Die Schnittnahtzeit war in der Revisionsgruppe länger, zeigte aber keinen signifikanten Unterschied.

Schlussfolgerung: Die bildlose roboterassistierte Revisionsendoprothetik von UKA zu TKA zeigt eine vergleichbare Operationszeit und Ausrichtungsgenauigkeit im Vergleich zur primären roboterassistierten Knietotalendoprothetik. Für beide Gruppen wurden eine vergleichbare Knochenresektion und konsekutiv vergleichbare Onlaygrößen beobachtet.

Schlüsselwörter

Retrospektive Studie $\cdot$ Fall-Kontroll-Studie $\cdot$ Präzision $\cdot$ Revisionsendoprothetik $\cdot$ Röntgenuntersu chung

private sectors: Where does the efficiency lie?: Private vs public operating time. ANZ J Surg 89:53-56. https://doi.org/10.1111/ans.14905

4. Di Martino A, Bordini B, Barile F et al (2020) Unicompartmental knee arthroplasty has higher revisions than total knee arthroplasty at long term follow-up: a registry study on 6453 prostheses. Knee Surg Sports Traumatol Arthrosc. https://doi. org/10.1007/s00167-020-06184-1

5. El-Galaly A, Kappel A, Nielsen PT, Jensen SL (2019) Revision risk for total knee arthroplasty converted from medial unicompartmental knee arthroplasty: comparison with primary and revision arthroplasties, based on mid-term results from the Danish knee arthroplasty registry. J Bone Joint Surg Am 101:1999-2006. https://doi.org/10 2106/JBJS.18.01468

6. Endoprothesenregister Deutschland (2020) EPRD Jahresbericht 2020

7. Ettinger M, Tücking L-R, Savov P (2020) Kinematic alignment in total knee arthroplasty with image- based and image-independent robotic support Orthopade 49:604-610. https://doi.org/10.1007/ s00132-020-03924-6

8. Jones GG, Kotti M, Wiik AV et al (2016) Gait comparison of unicompartmental and total knee arthroplasties with healthy controls. Bone Joint J 98-B:16-21. https://doi.org/10.1302/0301-620X. 98B10.BJJ.2016.0473.R1

9. Kayani B, Haddad FS (2019) Robotic total knee arthroplasty: clinical outcomes and directions for future research. Bone Joint Res 8:438-442. https:// doi.org/10.1302/2046-3758.810.BJR-2019-0175

10. Kayani B, Konan S, Huq SS et al (2019) Roboticarm assisted total knee arthroplasty has a learning curve of seven cases for integration into the surgical workflow but no learning curve effect for accuracy of implant positioning. Knee Surg Sports Traumatol Arthrosc 27:1132-1141. https://doi. org/10.1007/s00167-018-5138-5

11. Lee JK, Kim HJ, Park JO, Yang J-H (2018) Inferior outcome of revision of unicompartmental knee 
arthroplasty to total knee arthroplasty compared with primary total knee arthroplasty: systematic review and meta-analysis. Knee Surg Sports Traumatol Arthrosc 26:3403-3418. https://doi. org/10.1007/s00167-018-4909-3

12. Lei K, Liu L, Chen X et al (2021) Navigation and robotics improved alignment compared with PSI and conventional instrument, while clinical outcomes were similar in TKA: a network metaanalysis. Knee Surg Sports Traumatol Arthrosc. https://doi.org/10.1007/s00167-021-06436-8

13. Leta TH, Lygre SHL, Skredderstuen A et al (2016) Outcomes of unicompartmental knee arthroplasty after aseptic revision to total knee arthroplasty: a comparative study of 768 TKAs and 578 UKAs revised to TKAs from the Norwegian arthroplasty register (1994 to 2011). J Bone Joint Surg Am 98:431-440. https://doi.org/10.2106/JBJS.O. 00499

14. Liddle AD, Judge A, PanditH, Murray DW (2014) Adverse outcomes after total and unicompartmental knee replacement in 101,330 matched patients: a study of data from the National Joint Registry for England and Wales. Lancet 384:1437-1445. https://doi.org/10.1016/S0140-6736(14)60419-0

15. Liddle AD, Pandit $H$, Judge A, Murray DW (2015) Patient-reported outcomes after total and unicompartmental knee arthroplasty: a study of 14,076 matched patients from the National Joint Registry for England and Wales. Bone Joint J 97B:793-801. https://doi.org/10.1302/0301-620X. 97B6.35155

16. Liddle $A D$, Pandit $H$, Judge $A$, Murray DW (2016) Effect of surgical caseload on revision rate following total and unicompartmental knee replacement. JBone Joint Surg Am 98:1-8. https:// doi.org/10.2106/JBJS.N.00487

17. Lombardi AV, Kolich MT, Berend KR et al (2018) Revision of unicompartmental knee arthroplasty to total knee arthroplasty: Is it as good as a primary result? J Arthroplasty 33:S105-S108. https://doi. org/10.1016/j.arth.2018.03.023

18. Lunebourg A, Parratte S, Ollivier M et al (2015) Are revisions of unicompartmental knee arthroplasties more like a primary or revision TKA? J Arthroplasty 30:1985-1989. https://doi.org/10.1016/j.arth. 2015.05.042

19. Mahoney O, Kinsey T, Sodhi N et al (2020) Improved component placement accuracy with robotic-arm assisted total knee arthroplasty. J Knee Surg. https://doi.org/10.1055/s-0040-1715571

20. NJR Editorial Board (2016) National Joint Registry for England, Wales, Northern Ireland and the Isle of Man. 13th annual report

21. O'Donnell TMP, Abouazza O, Neil MJ (2013) Revision of minimal resection resurfacing unicondylar knee arthroplasty to total knee arthroplasty. J Arthroplasty 28:33-39. https://doi.org/10.1016/ j.arth.2012.02.031

22. Sarraf KM, Konan S, Pastides PS et al (2013) Bone loss during revision of unicompartmental to total knee arthroplasty. J Arthroplasty 28:1571-1574. https://doi.org/10.1016/j.arth.2013.02.003

23. Savov $P$, Tuecking L-R, Windhagen $\mathrm{H}$ et al (2021) Imageless robotic handpiece-assisted total knee arthroplasty: a learning curve analysis of surgical time and alignment accuracy. Arch Orthop Trauma Surg. https://doi.org/10.1007/s00402021-04036-2

24. Sekimura TK, Upfill-Brown A, Hsiue PP et al (2021) Trends in operative time and short-term outcomes after conventional and navigated total knee arthroplasty. Arthroplasty Today 8:188-193. https://doi.org/10.1016/j.artd.2021.02.015
25. Sodhi N, Khlopas A, Piuzzi NS et al (2018) The learning curve associated with robotic total knee arthroplasty. J Knee Surg 31:17-21. https://doi. org/10.1055/s-0037-1608809

26. Song E-K, Seon J-K, Yim J-H et al (2013) Roboticassisted TKA reduces postoperative alignment outliers and improves gap balance compared to conventional TKA. Clin Orthop 471:118-126. https://doi.org/10.1007/s11999-012-2407-3

27. Sun X, Su Z (2018) A meta-analysis of unicompartmental knee arthroplasty revised to total knee arthroplasty versus primary total knee arthroplasty. J Orthop Surg 13:158. https://doi.org/10. 1186/s13018-018-0859-1

28. Weber M, Worlicek M, Voellner F et al (2018) Surgical training does not affect operative time and outcome in total knee arthroplasty. PLoS ONE 13:e197850. https://doi.org/10.1371/journal. pone. 0197850

29. Wynn Jones H, Chan W, Harrison T et al (2012) Revision of medial Oxford unicompartmental knee replacement to a total knee replacement: similar to a primary? Knee 19:339-343. https://doi.org/10. 1016/j.knee.2011.03.006

30. Yun AG, Qutami M, Chen C-HM, Pasko KBD (2020) Management of failed UKA to TKA: conventional versus robotic-assisted conversion technique. Knee Surg Relat Res 32:38. https://doi.org/10. 1186/s43019-020-00056-1

31. Zhang J, Ndou WS, Ng N et al (2021) Roboticarm assisted total knee arthroplasty is associated with improved accuracy and patient reported outcomes: a systematic review and meta-analysis. Knee Surg Sports Traumatol Arthrosc. https://doi. org/10.1007/s00167-021-06464-4
MED UPDATE SEMINARE 2022

Ortho Trauma Update 2022

13. Orthopädie-Unfallchirurgie-

Update-Seminar

04.-05. März 2022

Berlin und Livestream

Wiss. Leitung:

Prof. Dr. Ralph Gaulke, Hannover

Prof. Dr. Klaus-Peter Günther, Dresden

Unter der Schirmherrschaft der BVOU/DGSP

www.ortho-trauma-update.com

Auskunft für alle Update-Seminare: med update GmbH

www.med-update.com

Tel.: 0611 - 736580

info@med-update.com 
Hier steht eine Anzeige.

黑 Springer 